\title{
Growth in early treated congenital hypothyroidism
}

\author{
D B Grant
}

\begin{abstract}
The growth of 361 children with congenital hypothyroidism diagnosed by screening was assessed by estimating mean values for height, weight, body mass index (BMI), and head circumference on each birthday up to the age of 4 years. In the group of children with severe congenital hypothyroidism (pretreatment plasma thyroxine $\leqslant 30 \mathrm{nmol} / \mathrm{l})$, the mean heights at 1 and 2 years were less than standards for healthy children, but this may be due to technical factors related to difficulties in measuring young infants and the method used to estimate height on each birthday. By the age of 3-4 years the values for mean height in the children with either severe or less severe congenital hypothyroidism were equal to or greater than those for healthy children. At all ages mean head circumference in boys and girls with severe congenital hypothyroidism was greater than standards for healthy children, but this only reached statistical significance in girls at 1 year. With the exception of the results for boys at 1 year, mean values for BMI were slightly greater in the children with severe congenital hypothyroidism. The mean BMI results for children with either severe or less severe congenital hypothyroidism were significantly greater than those for healthy French children at all ages, but they showed the same trends with increasing age. It is concluded that by the age of 3-4 years stature is essentially normal in children with early treated congenital hypothyroidism but that the increased head size reported before screening may still be evident in early infancy.

(Arch Dis Child 1994; 70: 464-468)
\end{abstract}

Although it is accepted that hypothyroidism acquired during childhood can impair adult stature despite adequate treatment, ${ }^{12}$ most studies have reported that growth is normal in children with congenital hypothyroidism detected by screening and treated from early infancy. ${ }^{3-7}$ Aronson et al, ${ }^{8}$ however, found some growth delay at the age of 1 year whereas Leger and Czernichow found-evidence of delayed growth at diagnosis with catch up during the first year. ${ }^{9}$ Leger and Czernichow also found that head size was increased at the time of diagnosis but returned to normal with treatment. ${ }^{9}$ In contrast, Aronson et $a l^{8}$ and Thompson et al ${ }^{10}$ reported persistently increased head size in their patients.

The Medical Research Council register has information on height, weight, and head circumference up to the age of 4-5 years in a cohort of children with congenital hypothyroidism born between 1982 and 1984 in the United Kingdom, allowing further study of growth in a large, unselected population of children with early treated hypothyroidism. This paper compares the growth of these children with previously published standards for healthy children. It also examines the relations between growth during the first four years and severity of hypothyroidism at diagnosis, birth weight, and social and ethnic family background.

\section{Subjects and methods}

DATA COLLECTION

Details of the children with congenital hypothyroidism and documentation of the initial diagnosis have been published previously. ${ }^{11} 12$ Subjects were followed up annually to the age of 5 years and paediatricians were sent a questionnaire asking for dated measurements of height, weight, and head circumference close to each birthday. Details of any changes in the dose of thyroxine during the previous year were also requested, together with the results of all thyroid function tests.

\section{SUBJECTS}

Four hundred and seventy two children with congenital hypothyroidism were born between 1982 and 1984. Of these, 418 (89\%) had measurements of plasma total thyroxine (TT4) concentration before treatment and also had complete follow up data to the age of 4 years.

In 27 of these children, the reported birth weight was less than $2.5 \mathrm{~kg}$. In view of the association between low birth weight and impaired growth, these children have been excluded from the current analysis, as have a further 30 children in whom birth weight was not recorded, leaving 361 subjects (112 boys and 249 girls) with birth weights in the normal range who also had documentation of the severity of hypothyroidism before treatment (pretreatment TT4 $\leqslant 30 \mathrm{nmol} / \mathrm{l}$,
Correspondence to: Dr D B Grant, Hospital for Sick Children, Great Wrmond Stre Accepted 11 February 1994
Institute of Child Health, London 
Table 1 Mean (SD) height (cm) estimated for each birthday from 1 to 4 years for the children with congenital hypothyroidism grouped according to pretreatment thyroxine (TT4) ( $\leqslant 30$ nmoll and >30 nmoll) and compared with mean (SD) heights in healthy children from the United Kingdom ${ }^{14}$

\begin{tabular}{|c|c|c|c|}
\hline \multirow[b]{2}{*}{ Age (years) } & \multicolumn{2}{|c|}{ Children with congenital hypothyroidism } & \multirow[b]{2}{*}{$\begin{array}{l}\text { Standards of } \\
\text { Tanner et } \mathrm{al}^{14}\end{array}$} \\
\hline & $\begin{array}{l}\text { Pretreatment } \\
T T 4 \leqslant 30 \text { noll }\end{array}$ & $\begin{array}{l}\text { Pretreatment } \\
T T 4>30 \mathrm{nmol} /\end{array}$ & \\
\hline \multicolumn{4}{|l|}{ Boys } \\
\hline 1 & $74 \cdot 0(3 \cdot 4)^{\star}[n=28]$ & $75 \cdot 4(2 \cdot 0)[n=30]$ & $76 \cdot 3(2 \cdot 7)$ \\
\hline 2 & $85 \cdot 7(3 \cdot 3)[n=48]$ & $86.2(3.2)[n=51]$ & $86.9(3.3)$ \\
\hline 3 & $94 \cdot 2(4 \cdot 0)[\mathrm{n}=49]$ & $94.8(3.5)[\mathrm{n}=56]$ & $94.2(3.8)$ \\
\hline 4 & $101 \cdot 6(4 \cdot 9)[\mathrm{n}=51]$ & $102 \cdot 7(4 \cdot 0)[\mathrm{n}=57]$ & $101 \cdot 6(4 \cdot 3)$ \\
\hline \multicolumn{4}{|l|}{ Girls } \\
\hline 1 & $73 \cdot 6(3 \cdot 1)[n=59]$ & $73 \cdot 8(2 \cdot 9)[n=72]$ & $74 \cdot 2(2 \cdot 7)$ \\
\hline 2 & $84 \cdot 0(3 \cdot 0)^{\star}[\mathrm{n}=94]$ & $84.5(3 \cdot 4)^{\star}[n=117]$ & $85 \cdot 6(3 \cdot 8)$ \\
\hline 3 & $93.3(3.2)[\mathrm{n}=109]$ & $93.1(3.6)[n=119]$ & $93.0(3.8)$ \\
\hline 4 & $100.9(3.8)[n=110]$ & $100 \cdot 6(4 \cdot 3)[n=119]$ & $100 \cdot 4(4 \cdot 3)$ \\
\hline
\end{tabular}

^Significantly different from the mean value for normal standards $(p<0 \cdot 01)$.

168 children; pretreatment TT4 $>30 \mathrm{nmol} / \mathrm{l}$, 193 children) and growth data up to 4 years of age. Information was also available for father's occupation (155 non-manual; 204 manual or unemployed; two missing), and mother's ethnic background (34 Asian; 327 non-Asian).

\section{MEASUREMENTS OF HEIGHT, WEIGHT, AND}

HEAD CIRCUMFERENCE

Annual measurements were not always obtained over the period 1-4 years. For example, only 294 children had measurements of height and weight between the ages of 6 and 18 months of age; the numbers of children with measurements of height and weight between the ages of 18 and 30 months, 30 and 42 months, and 42 and 54 months were 329 , 326 , and 335 respectively. Many measurements were not obtained close to the time of a birthday; only 189 children were measured within six weeks of their first birthday, 188 within six weeks of their second birthday, 184 within six weeks of their third birthday, and 177 within six weeks of their fourth birthday. Head circumference was measured between the ages of 6 and 18 months in 284 children, between 18 and 30 months in 228, between 30 and 42 months in 163, and between 42 and 54 months in 189 . The corresponding measurements made within six weeks of a birthday were $172,106,66$, and 73 respectively.

ESTIMATION OF HEIGHT, WEIGHT, AND HEAD CIRCUMFERENCE ON EACH BIRTHDAY

Height, weight, and head circumference on each birthday were estimated by linear interpolation using the following formulas, which assume that the rate of growth between any two measurements is constant:

Btdy $\mathrm{Ht}=\mathrm{Ht} 1+\left((\mathrm{Ht} 2-\mathrm{Ht} 1)^{\star}(\right.$ Btdy Age - Age 1$\left.)\right) /($ Age2 - Age 1$)$

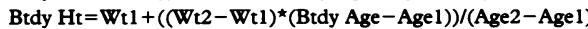
Btdy $\mathrm{HC}=\mathrm{HC} 1+\left((\mathrm{HC} 2-\mathrm{HC} 1)^{\star}(\right.$ Btdy Age - Age1 $\left.)\right) /($ Age2 - Age 1$)$

Btdy $\mathrm{Ht}, \mathrm{Wt}, \mathrm{HC}$ are the estimated values of height, weight, and head circumference in $\mathrm{cm}$ or $\mathrm{kg}$ on a specified birthday; $\mathrm{Ht} 1, \mathrm{Wt} 1, \mathrm{HC} 1$, and Age 1 are the last recorded measurements in $\mathrm{cm}$ or $\mathrm{kg}$ and age before the birthday; $\mathrm{Ht} 2$, Wt2, HC2, and Age2 are the next recorded measurements in $\mathrm{cm}$ or $\mathrm{kg}$ and age after the birthday. Results were excluded if Age2-Age1 was more than 730 days.

As growth during early infancy follows an exponential curve, ${ }^{13}$ these formulas will tend to underestimate growth, especially in the first two years and particularly when the measurements used to estimate growth are obtained a considerable time from the target birthday. To assess the extent of this underestimation, all estimates were recalculated using only paired measurements in which one was made within six weeks of the relevant birthday. Almost identical results for height, weight, and head circumference were obtained for the second, third, and fourth birthdays using the two methods and the original results have been retained. At 1 year of age, however, the mean values for height for boys and girls were greater by $0.8 \mathrm{~cm}$, and for head circumference by $0.6 \mathrm{~cm}$ (boys) and $0.3 \mathrm{~cm}$ (girls) using the over six week exclusion, and the latter results have been used in the present analysis.

Body mass index (BMI) was calculated using the equation:

$\left.B M I=(B t d y) t(\mathrm{~kg}) / \mathrm{Btdy} \mathrm{Ht}^{2}(\mathrm{~cm})\right) / 10000$

\section{STATISTICAL ANALYSIS OF RESULTS}

The mean (SD) values for estimated height, BMI, and head circumference and the medians (with 10th minus 90th centiles) for estimated weight for boys and girls with severe (pretreatment TT4 $\leqslant 30 \mathrm{nmol} / \mathrm{l}$ ) and less severe (pretreatment TT4 $>30 \mathrm{nmol} / \mathrm{l}$ ) congenital hypothyroidism were compared with one another and with published standards for height and weight, ${ }^{14} \mathrm{BMI},{ }^{15}$ and head circumference ${ }^{16}$ in normal children using $t$ tests to assess differences between mean values. Correlation coefficients were calculated to examine the relation between growth at each birthday and birth weight or daily dose of thyroxine, expressed as either $\mu \mathrm{g} / \mathrm{kg}$ or $\mu \mathrm{g} / \mathrm{m}^{2}$. The interaction of the variables birth weight, sex, father's occupation, mother's ethnic background, and initial severity of hypothyroidism on growth were examined by linear regression with height, weight, BMI, or head circumference as the dependent variable (SAS Institute, 1987). A p value of 0.01 or less was taken to indicate statistical significance.

\section{Results}

COMPARISON BETWEEN CHIIDREN WITH SEVERE AND LESS SEVERE HYPOTHYROIDISM

During the first four years the mean height in the boys with severe hypothyroidism was $0.5-1.4 \mathrm{~cm}$ less than that for boys with less severe hypothyroidism (table 1); in the girls the differences were smaller and less consistent. Similarly, median weight in the boys with severe hypothyroidism was $0.1-0.7 \mathrm{~kg}$ less in the group with severe hypothyroidism, whereas in the girls the median weight was either the same or $0.2-0.3 \mathrm{~kg}$ greater in the severe group (table 2). In both boys and girls BMI was 
Table 2 Median weight (with 10th to 90th centiles) ( $\mathrm{kg}$ ) estimated for each birthday from 1 to 4 years for the children with congenital hypothyroidism grouped according to pretreatment thyroxine (TT4) ( $\leqslant 30$ nmoll and $>30$ nmoll) and compared with the mean values (with 10th to 90th centiles) for healthy children from the United Kingdom ${ }^{14}$

\begin{tabular}{clcl}
\hline & \multicolumn{2}{l}{ Children with congenital hypothyroidism } & \\
\cline { 2 - 4 } Age (years) & $\begin{array}{l}\text { Pretreatment } \\
\text { TT4 } \leqslant 30 \text { nmoll }\end{array}$ & $\begin{array}{l}\text { Pretreatment } \\
\text { TT4 }>30 \text { nmoll }\end{array}$ & $\begin{array}{l}\text { Standards of } \\
\text { Tanner et al }{ }^{14}\end{array}$ \\
\hline Boys & & & \\
1 & $10 \cdot 1(9 \cdot 3-12 \cdot 4)[n=28]$ & $10 \cdot 8(8 \cdot 6-11 \cdot 9)[n=30]$ & $10 \cdot 2(8 \cdot 8-11 \cdot 7)$ \\
2 & $12 \cdot 8(11 \cdot 1-14 \cdot 9)[n=48]$ & $13 \cdot 1(10 \cdot 8-14 \cdot 8)[n=51]$ & $12 \cdot 7(11 \cdot 0-14 \cdot 6)$ \\
3 & $15 \cdot 3(13 \cdot 0-18 \cdot 2)[n=49]$ & $15 \cdot 4(12 \cdot 8-17 \cdot 9)[n=56]$ & $14 \cdot 7(12 \cdot 7-16 \cdot 9)$ \\
4 & $17 \cdot 5(14 \cdot 9-20 \cdot 6)[n=51]$ & $17 \cdot 7(14 \cdot 3-20 \cdot 6)[n=57]$ & $16 \cdot 6(14 \cdot 3-19 \cdot 1)$ \\
Girls & $9 \cdot 9(8 \cdot 5-11 \cdot 7)[n=59]$ & $9 \cdot 6(8 \cdot 2-11 \cdot 0)[n=72]$ & $9 \cdot 7(8 \cdot 4-11 \cdot 2)$ \\
1 & $12 \cdot 1(10 \cdot 7-14 \cdot 2)[n=94]$ & $12 \cdot 1(10 \cdot 5-14 \cdot 0)[n=117]$ & $12 \cdot 2(10 \cdot 4-14 \cdot 1)$ \\
2 & $14 \cdot 4(12 \cdot 8-16 \cdot 9)[n=109]$ & $14 \cdot 4(12 \cdot 2-16 \cdot 5)[n=119]$ & $14 \cdot 3(12 \cdot 3-16 \cdot 4)$ \\
3 & $16 \cdot 6(14 \cdot 9-19 \cdot 9)[n=110]$ & $16 \cdot 4(14 \cdot 1-19 \cdot 0)[n=119]$ & $16 \cdot 3(14 \cdot 1-18 \cdot 8)$ \\
4 & & & \\
\hline
\end{tabular}

Table 3 Mean (SD) BMI calculated for each birthday from 1 to 4 years for the children with congenital hypothyroidism grouped according to pretreatment thyroxine (TT4) $(\leqslant 30$ nmoll and $>30$ nmoln) and compared with values for healthy French children. ${ }^{15}$ Mean $B M I$ values for both groups of children with congenital hypothyroidism were significantly greater than the French mean $B M I$ values at all ages $(p<0.01)$

\begin{tabular}{|c|c|c|c|}
\hline \multirow[b]{2}{*}{ Age (years) } & \multicolumn{2}{|c|}{ Children with congenital hypothyroidism } & \multirow{2}{*}{$\begin{array}{l}\text { Standards of } \\
\text { Roland-Cachera } \\
\text { et a } 1^{15}\end{array}$} \\
\hline & $\begin{array}{l}\text { Pretreatment } \\
T T 4 \leqslant 30 \text { nmoll }\end{array}$ & $\begin{array}{l}\text { Pretreatment } \\
T T 4>30 \mathrm{nmol} /\end{array}$ & \\
\hline \multicolumn{4}{|l|}{ Boys } \\
\hline $\begin{array}{l}1 \\
2 \\
3 \\
4\end{array}$ & $\begin{array}{l}19 \cdot 0(1 \cdot 8)[n=28] \\
17 \cdot 5(1 \cdot 4)[n=48] \\
17 \cdot 4(1 \cdot 4)[n=49] \\
17 \cdot 0(1 \cdot 4)[n=51]\end{array}$ & $\begin{array}{l}18 \cdot 4(1 \cdot 9)[n=30] \\
17 \cdot 6(1 \cdot 7)[n=51] \\
17 \cdot 1(1 \cdot 5)[n=56] \\
16 \cdot 7(1 \cdot 5)[n=57]\end{array}$ & $\begin{array}{l}17 \cdot 7(1 \cdot 5)[n=209] \\
16 \cdot 6(1 \cdot 2)[n=183] \\
16 \cdot 1(1 \cdot 1)[n=104] \\
15 \cdot 8(1 \cdot 1)[n=145]\end{array}$ \\
\hline \multicolumn{4}{|c|}{  } \\
\hline $\begin{array}{l}1 \\
2 \\
3 \\
4\end{array}$ & $\begin{array}{l}18 \cdot 3(1 \cdot 7)[n=59] \\
17 \cdot 5(1 \cdot 7)[n=94] \\
16 \cdot 9(1 \cdot 4)[n=109] \\
16 \cdot 7(1 \cdot 3)[n=110]\end{array}$ & $\begin{array}{l}17 \cdot 6(1 \cdot 6)[n=72] \\
17 \cdot 2(1 \cdot 4)[n=117] \\
16 \cdot 6(1 \cdot 2)[n=119] \\
16 \cdot 3(1 \cdot 3)[n=119]\end{array}$ & $\begin{array}{l}17 \cdot 4(1 \cdot 4)[n=197] \\
16 \cdot 2(1 \cdot 2)[n=170] \\
16 \cdot 0(1 \cdot 2)[n=100] \\
15 \cdot 6(1 \cdot 1)[n=132]\end{array}$ \\
\hline
\end{tabular}

Table 4 Mean (SD) head circumference ( $\mathrm{cm}$ ) estimated for each birthday from 1 to 4 years for children with congenital hypothyroidism grouped according to pretreatment thyroxine (TT4) ( $\leqslant 30$ nmoll and >30 nmoll) and compared with mean (SD) head circumference in healthy British children ${ }^{16}$

\begin{tabular}{|c|c|c|c|}
\hline \multirow[b]{2}{*}{ Age (years) } & \multicolumn{2}{|c|}{ Children with congenital hypothyroidism } & \multirow[b]{2}{*}{$\begin{array}{l}\text { Standards of } \\
\text { Ounsted et } \mathrm{al}^{16}\end{array}$} \\
\hline & $\begin{array}{l}\text { Pretreatment } \\
T T 4 \leqslant 30 \text { nmoll }\end{array}$ & $\begin{array}{l}\text { Pretreatment } \\
\text { TT4 }>30 \mathrm{nmol}\end{array}$ & \\
\hline \multicolumn{4}{|l|}{ Boys } \\
\hline $\begin{array}{l}1 \\
2 \\
3 \\
4\end{array}$ & $\begin{array}{l}48 \cdot 2(1 \cdot 7)[n=25] \\
50 \cdot 6(1 \cdot 7)[n=23] \\
52 \cdot 0(1 \cdot 9)[n=18] \\
52 \cdot 3(1.9)[n=19]\end{array}$ & $\begin{array}{l}47.3(1 \cdot 3)[n=27] \\
49 \cdot 8(1 \cdot 4)[n=34] \\
50.9(1.5)[n=30] \\
51.8(1.5)[n=26]\end{array}$ & $\begin{array}{l}47 \cdot 6(1 \cdot 4)[n=154] \\
50 \cdot 1(1 \cdot 5)[n=145] \\
51 \cdot 4(1 \cdot 5)[n=143] \\
52 \cdot 1(1 \cdot 5)[n=137]\end{array}$ \\
\hline \multicolumn{4}{|r|}{ 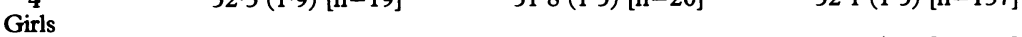 } \\
\hline $\begin{array}{l}1 \\
2 \\
3 \\
4\end{array}$ & $\begin{array}{l}46 \cdot 9(1 \cdot 3)[n=60]^{\star} \dagger \\
49 \cdot 1(1 \cdot 3)[n=54] \\
50 \cdot 3(1 \cdot 3)[n=43] \\
51 \cdot 0(1 \cdot 4)[n=48]\end{array}$ & $\begin{array}{l}46.0(1.6)[n=60] \\
48 \cdot 8(1.4)[n=63] \\
50.0(1.4)[n=52] \\
50.7(1.5)[n=45]\end{array}$ & $\begin{array}{l}46 \cdot 1(1 \cdot 2)[n=127] \\
48 \cdot 6(1 \cdot 3)[n=118] \\
49 \cdot 8(1 \cdot 4)[n=113] \\
50 \cdot 7(1 \cdot 4)[n=115]\end{array}$ \\
\hline
\end{tabular}

*Significantly different from the mean for less severe hypothyroidism $(p<0.01)$.

tSignificantly different from the mean for normal standards $(p<0 \cdot 01)$.

slightly greater in the children with severe hypothyroidism, apart from the values for boys at 2 years (table 3 ). None of the differences for mean height, weight, or BMI between the groups with severe and less severe hypothyroidism reached statistical significance.

Table 4 gives the mean values for head circumference. In boys and girls the mean head circumference was $0.3-1.1 \mathrm{~cm}$ greater in the children with more severe hypothyroidism. Only in girls at 1 year did this reach statistical significance $(t=3 \cdot 18 ; \mathrm{p}<0.002)$.

COMPARISON WITH STANDARDS FOR HEALTHY CHILDREN

Table 1 compares the mean heights of the children with congenital hypothyroidism at each birthday with standards for healthy children published in $1966 .{ }^{14}$ At 1 and 2 years the mean heights for boys and girls with severe hypothyroidism were $0 \cdot 6-2 \cdot 3 \mathrm{~cm}$ less than the normal standards; the difference was significant at 1 year in the boys $(t=3.54 ; \mathrm{p}<0.01)$ and at 2 years in the girls $(t=5 \cdot 16 ; \mathrm{p}<0.001)$. At the ages of 1 and 2 years the mean values for height in boys and girls with less severe hypothyroidism were also less than those for healthy children, and this was significant at 2 years in the girls $(t=3.44 ; \mathrm{p}<0.01)$. By the age of 3-4 years the mean heights for boys and girls in the two hypothyroid groups were the same as those for the normal children or $0.3-1 \cdot 1 \mathrm{~cm}$ greater.

Table 2 compares the median weights for the children with congenital hypothyroidism with the 1966 standards. At 1 and 2 years the boys with severe congenital hypothyroidism were similar to normal boys but at 3 and 4 years they were heavier. At all ages the boys with less severe hypothyroidism were heavier than the normal boys. In contrast, median weights for the girls in the two hypothyroid groups were similar to those for normal girls.

Table 3 compares the mean values for BMI in the children with congenital hypothyroidism and in healthy children. ${ }^{15}$ In both sexes the trends in BMI with age are similar. At all ages the mean BMI for boys and girls in each hypothyroid group was significantly greater than that for normal French children $(p<0.01-0.001)$.

At all ages the mean head circumference for boys and girls with severe hypothyroidism was greater than that for normal children but this only reached statistical significance in girls at 1 year. In the boys with less severe hypothyroidism the mean head circumference was $0.3-0.5 \mathrm{~cm}$ less than for normal boys; the values for girls in this group were close to those for healthy girls.

\section{RELATION OF GROWTH TO BIRTH WEIGHT AND} FAMILY BACKGROUND

The mean (SD) birth weight for the 361 subjects was $3.50(0.48) \mathrm{kg}$. There was no significant difference between the mean birth weights for boys $(3.57(0.46) \mathrm{kg})$ and girls $(3.47(0.50) \mathrm{kg})$, or infants with pretreatment TT4 concentrations $\leqslant 30 \mathrm{nmol} / 1(3.51(0.51)$ $\mathrm{kg})$ or $>30 \mathrm{nmol} / 1(3.50(0.47) \mathrm{kg})$. The mean birth weight for infants with fathers in nonmanual occupations $(3.58(0.48) \mathrm{kg})$ was significantly higher than that for subjects with fathers who were either in manual occupations or unemployed $(3.44(0.48) \mathrm{kg})(t=2.80$; $\mathrm{p}<0.01)$. The mean birth weight for infants born to mothers of an Asian background (3.29 $(0.43) \mathrm{kg})$ was significantly less than for infants of non-Asian mothers (3.52 (0.49) $\mathrm{kg})$ $(t=2 \cdot 64 ; \mathrm{p}<0.01)$.

Birth weight showed significant relations with height, weight, and head circumference at all ages, and with BMI after the age of 1 year. Regression analysis with birth weight and sex as the independent variables (table 5) indicates that $11-16 \%$ of the variation in 
Table 5 Linear regression for height, weight, and BMI estimated for each birthday against birth weight and sex in children with congenital hypothyroidism

\begin{tabular}{|c|c|c|c|c|}
\hline & \multicolumn{4}{|l|}{ Age (years) } \\
\hline & 1 & 2 & 3 & 4 \\
\hline $\begin{array}{l}\text { Degrees of freedom } \\
\text { Height }(\mathrm{cm})\end{array}$ & 2,186 & 2,307 & 2,330 & 2,334 \\
\hline $\begin{array}{l}\text { Birth weight (kg) } \\
\text { Effect (SE) } \\
\text { Sex/female }\end{array}$ & $0.22(0.04)^{\star}$ & $0.20(0.04)^{\star}$ & $0.23(0.04)^{\star}$ & $0.26(0.05)^{\star}$ \\
\hline $\begin{array}{l}\text { Effect (SE) } \\
R^{2} \\
\text { Weight (ko) }\end{array}$ & $\begin{array}{l}-0.74(0.44) \\
0.16\end{array}$ & $\begin{array}{l}-1.48(0.37)^{\star} \\
0.14\end{array}$ & $\begin{array}{l}-1 \cdot 06(0.40) \ddagger \\
0.13\end{array}$ & $\begin{array}{l}-1 \cdot 10(0 \cdot 47) \\
0.11\end{array}$ \\
\hline $\begin{array}{l}\text { Weight (kg) } \\
\text { Birth weight (kg) } \\
\text { Effect (SE) }\end{array}$ & $0.84(0.16)^{\star}$ & $1.02(0.16)^{\star}$ & $1.22(0 \cdot 18)^{\star}$ & $1.42(0.22)^{\star}$ \\
\hline $\begin{array}{l}\text { Sex/female } \\
\text { Effect (SE) } \\
R^{2}\end{array}$ & $\begin{array}{l}-0.60(0.17) \dagger \\
0.20\end{array}$ & $\begin{array}{l}-0.58(0.16) \dagger \\
0.16\end{array}$ & $\begin{array}{l}-0.70(0.19) \dagger \\
0.17\end{array}$ & $\begin{array}{l}-0.69(0.23) \ddagger \\
0.15\end{array}$ \\
\hline $\begin{array}{l}\text { BMI } \\
\text { Birth weight (kg) }\end{array}$ & & & & \\
\hline $\begin{array}{l}\text { Effect (SE) } \\
\text { Sex/female }\end{array}$ & $0.45(0.25) \ddagger$ & $0.59(0.18) \dagger$ & $0.57(0.15) \dagger$ & $0.52(0.15) \dagger$ \\
\hline$R^{2}{ }^{\text {Effect (SE) }}$ & $\begin{array}{l}-0.73(0.28) \\
0.06\end{array}$ & $\begin{array}{r}-0.19(0.18) \\
0.04\end{array}$ & $\begin{array}{l}-0.41(0.16) \\
0.06\end{array}$ & $\begin{array}{l}-0.30(0 \cdot 16) \\
0.05\end{array}$ \\
\hline
\end{tabular}

${ }^{\star} \mathrm{p}<0.0001 ; \mathrm{tp}<0.001 ; \neq \mathrm{p}<0.01$.

height, $15-20 \%$ of the variation in weight, but only $4-6 \%$ of the variation in $\mathrm{BMI}$ could be accounted for by the effects of these two variables. Addition of father's occupation, mother's ethnic background, and severity of hypothyroidism to the regression model did not improve the correlation coefficient. In contrast, although a combination of birth weight and sex accounted for $19-24 \%$ of the variation in head circumference, addition of father's occupation, mother's ethnic background, and severity of hypothyroidism as further independent variables increased the correlation coefficient to $0 \cdot 29-0.36$ (table 6).

RELATION OF GROWTH TO DOSE OF THYROXINE No significant correlations were obtained between height or head circumference and daily dose of thyroxine expressed as $\mu \mathrm{g} / \mathrm{kg}$ or $\mu \mathrm{g} / \mathrm{m}^{2}$ on each birthday.

\section{Discussion}

These results indicate that by the age of 3-4 years growth is essentially normal in children with congenital hypothyroidism detected by neonatal screening who have been treated from early infancy. This is in general agreement with results obtained by others in smaller groups of children with congenital hypothyroidism. ${ }^{4-6}$

Table 6 Linear regression for head circumference in children with congenital hypothyroidism estimated on each birthday from 1 to 4 years against birth weight, sex, father's occupation, mother's ethnic background, and initial severity of hypothyroidism

\begin{tabular}{|c|c|c|c|c|}
\hline & \multicolumn{4}{|l|}{ Age (years) } \\
\hline & 1 & 2 & 3 & 4 \\
\hline $\begin{array}{l}\text { Degrees of freedom } \\
\text { Birth weight }(\mathrm{kg})\end{array}$ & 5,166 & 5,167 & 5,137 & 5,131 \\
\hline $\begin{array}{l}\text { Effect (SE) } \\
\text { Sex/female }\end{array}$ & $0.91(0.22)$ & $0.79(0.20) \dagger$ & $0.71(0.24) \ddagger$ & $0.76(0.27) \ddagger$ \\
\hline $\begin{array}{l}\text { Sex/female } \\
\text { Effect (SE) }\end{array}$ & $-1.07(0.23) \dagger$ & $-0.96(0.22)$ & $-0.89(0.25) \dagger$ & $-1.05(0.26)^{\star}$ \\
\hline $\begin{array}{l}\text { Father's occupation } \\
\text { Effect (SE) } \\
\text { Mother's ethnic bac }\end{array}$ & $\begin{array}{l}\text { manual } \\
0.54(0.21) \\
\text { ind/Asian }\end{array}$ & $0.55(0.21)$ & $0.66(0.24) \ddagger$ & $0.68(0.24) \ddagger$ \\
\hline $\begin{array}{l}\text { Effect (SE) } \\
\text { Severity of hypothyr }\end{array}$ & $\begin{array}{l}-1 \cdot 17(0.42) \ddagger \\
\mathrm{n} / \text { initial TT } 4 \leqslant 3\end{array}$ & $\begin{array}{l}-1.06(0.45) \\
\mathrm{nmol} / /\end{array}$ & $-1.33(0.50) \ddagger$ & $-1.56(0.58) \ddagger$ \\
\hline$R^{2}$ & $\begin{array}{l}0.67 \\
0.36\end{array}$ & $\begin{array}{l}0.32 \cdot 0.32) \\
0.30\end{array}$ & $\begin{array}{l}0.41(0.23) \\
0.30\end{array}$ & $\begin{array}{l}0.23(0.23) \\
0.29\end{array}$ \\
\hline
\end{tabular}

${ }^{\star} \mathrm{p}<0.0001 ; \mathrm{tp}<0.001 ; \neq \mathrm{p}<0.01$
Aronson et al, however, reported some delay in growth at 1 year of age. ${ }^{8}$ In the present study the mean height for the boys and girls with either severe or less severe congenital hypothyroidism at 1 and 2 years was less than the standards described by Tanner et al in $1966^{14}$; this difference was more marked in the children with relatively severe hypothyroidism. We believe that these findings may be largely related to technical factors, however, rather than representing a significant disturbance in growth in children with early treated congenital hypothyroidism. Firstly, linear interpolation was used to estimate height on each birthday and as already noted this will tend to lead to some underestimation, even when only measurements obtained fairly close to each birthday are used. Secondly, the results are based on measurements provided by a large number of paediatricians across the country and it seems likely that difficulties in measuring young children in routine clinical settings, particularly assessing supine length, probably contributed to the lower mean values obtained at 1 and 2 years. Thirdly, the absence of any statistically significant differences between the mean heights of the children with severe and less severe congenital hypothyroidism provides further evidence that early treated congenital hypothyroidism does not have an important effect on growth during the first two years.

Observations made before the introduction of neonatal screening indicated that head size appeared to be increased in children with congenital hypothyroidism despite long term treatment with thyroxine. ${ }^{17} 18$ Although Leger and Czernichow found that in infants with congenital hypothyroidism detected by screening the mean head size was increased at diagnosis, with treatment it returned to normal by the age of 1 year. ${ }^{9}$ This is in contrast with results described by Aronson et $a l^{8}$ and Thompson et $a l .{ }^{10}$ In these two studies, mean head circumference in the children with congenital hypothyroidism remained consistently above the mean values for the normal standards used. We found that head circumference was greater in the children with more severe hypothyroidism at all ages, and that this was statistically significant in girls at 1 year. The mean values for boys and girls with severe congenital hypothyroidism were also consistently greater than the mean values given by Ounsted et al for healthy children living in Oxfordshire, ${ }^{16}$ significantly so at 1 year in the girls. These findings suggest that during the first four years head size may remain slightly greater than normal in children with severe congenital hypothyroidism, despite treatment from an early age.

There are no appropriate United Kingdom standards for BMI in early childhood and we have used reference standards for healthy French children. ${ }^{15}$ Our results indicate that mean BMI for boys and girls with congenital hypothyroidism is appreciably greater than in normal French children. We also found that mean BMI was slightly greater at all ages in the children with more severe hypothyroidism, but this never reached statistical significance, 
unlike the differences between the children in either of the hypothyroid groups and the results for healthy French children. We therefore believe that our findings may represent a more general difference between children in France and the United Kingdom, rather than indicating that congenital hypothyroidism is associated with increased BMI.

Although these results were obtained in children with congenital hypothyroidism, they may be of wider relevance to growth in healthy children. In particular, our observation that there is a significant correlation between birth weight and growth up to the age of 4 years (particularly for head size) is of interest, as are the effects of family social and ethnic background on head size.

We thank all the paediatricians across the UK who have provided follow up information on their patients with congenital hypothyroidism. The study was supported by the Medical Research Council.

1 Rivkees SA, Bode HH, Crawford JD. Long term growth in juvenile acquired hypothyroidism: the failure to achieve
normal adult stature. $N$ Engl f Med 1988; 318: 599-602.

2 Pantsiotou S, Stanhope R, Uruena M, Preece MA, Grant DB. Growth prognosis and growth after menarche in DB. Growth prognosis and growth after menarche in primary

3 Hulse JA, Grant DB, Jackson D, Clayton B. Growth, development and reassessment of hypothyroid infants diagnosed by screening. BMF 1982; 284: 1435-7.

4 New England Congenital Hypothyroidism Collaborative. Characteristics of infantile hypothyroidism discovered on neonatal screening. F Pediatr 1984; 104: 539-44.
5 Bucher H, Prader A, Illig R. Head circumference, height, bone age and weight in 103 children with congenital hypothyroidism before and during thyroid hormone hypothyroidism before and during thyroid hormone replacem

6 Moschini L, Costa P, Marinelli E, et al. Longitudinal assessment of children with congenital hypothyroidism detected by neonatal screening. Helvetica Paediatrica Acta 1986; 41: 415-24.

7 Fisher DA, Foley BL. Early treatment of congenital hypothyroidism. Pediatrics $1989 ; 83$ : 785-9.

8 Aronson R, Ehrlich RM, Bailey JD, Rovet JF. Growth in children with congenital hypothyroidism detected by neonatal screening. F Pediatr 1990; 116: 33-7.

9 Leger J, Czernichow P. Congenital hypothyroidism: decreased growth velocity in the first weeks of life. Biol decreased growth velocity
Neonate 1989; 55: $218-23$.

10 Thompson GN, McCrossin RB, Penfold JL, Woodroffe P, Rose WA, Robertson EF. Management and outcome of children with congenital hypothyroidism detected by neonatal screening in South Australia. Med f Aust 1986; 145: $18-22$

11 Grant DB, Smith I. Survey of neonatal screening for primary hypothyroidism in England, Wales and Northern Ireland 1982-4. BMF 1988; 296: 1355-8.

12 Grant DB, Smith I, Fuggle PW, Tokar S, Chapple J. Congenital hypothyroidism detected by neonatal screening: relationship between biochemical severity and screening: relationship between biochemical severity and

13 Karlberg J, Engström I, Karlberg P, Fryer JG. Analysis of linear growth using a mathematical model. I. From birth to 3 years. Acta Paediatr Scand 1987; 76: 478-88.

14 Tanner JM, Whitehosue RH, Takaishi M. Standards from birth to maturity for height, weight, height velocity, and weight velocity: British children, 1965. Arch Dis Child 1966; 41: 613-35.

15 Rolland-Cachera MF, Cole TJ, Sempé M, Tichet J, Rossignol C, Charraud A. Body mass index variations between birth and 87 years. Eur $\mathcal{f}$ Clin Nutr 1991; 45: between

16 Ounsted M, Moar VA, Scott A. Head circumference charts updated. Arch Dis Child 1985; 60: 936-9.

7 Burt L, Kulin HE. Head circumference in children with short stature secondary to primary hypothyroidism. Pediatrics 1977; 59: 628-30.

18 Frost GJ, Parkin JM. Management of patients with congenital hypothyroidism. BMF 1985; 290: 1485--9. 